\title{
Terminology matters! Why difference is not incompleteness and how early child bilinguals are heritage speakers
}

International Journal of Bilingualism 2018, Vol. 22(5) 564-582 (C) The Author(s) 2016 Article reuse guidelines: sagepub.com/journals-permissions DOI: $10.1177 / 13670069 \mid 6654355$ journals.sagepub.com/home/ijb

@SAGE

\section{Tanja Kupisch}

Universität Konstanz, Germany

UiT, The Arctic University of Norway, Norway

\section{Jason Rothman}

University of Reading, UK

UiT, The Arctic University of Norway, Norway

\begin{abstract}
This paper integrates research on child simultaneous bilingual acquisition more directly into the heritage language acquisition literature. The child simultaneous bilingual literature mostly focuses on development in childhood, whereas heritage speakers are often tested at an endstate in adulthood. However, insights from child simultaneous bilingual acquisition must be considered in heritage language acquisition theorizing precisely because many heritage speakers demonstrate the adult outcomes of child simultaneous bilingual acquisition. Data from child simultaneous bilingual acquisition raises serious questions for the construct of incomplete acquisition, a term broadly used in heritage language acquisition studies to describe almost any difference heritage speakers display from baseline controls (usually monolinguals). We offer an epistemological discussion related to incomplete acquisition, highlighting the descriptive and theoretical inaccuracy of the term. We focus our discussion on two of several possible causal factors that contribute to variable competence outcomes in adult heritage speakers: input and formal instruction in the heritage language. We conclude by offering alternative terminology for heritage speaker outcomes.
\end{abstract}

\section{Keywords}

Heritage language, heritage speaker bilinguals, simultaneous bilinguals, incomplete acquisition, input, schooling

\section{Corresponding author:}

Jason Rothman, University of Reading, Whiteknights, PO Box 217, Reading, Berkshire RG6 6AH, UK. Email: j.rothman@reading.ac.uk 


\section{Introduction}

Prior to the early 1960s, the commonly accepted view of bilingualism — held even by many psychologists and linguists - was that it was subtractive for normal development. Bilingualism was considered a 'bad thing', at least with regards to cognitive and linguistic development. Bilingualism was thought to confuse the child, presumably due to some type of cognitive overload related to the complex task of acquiring, maintaining and balancing two languages. As a result, it was often held that exposing children to more than one language would likely result in so-called imperfect acquisition of both languages. In the extreme, it was believed that bilingualism conferred disadvantages for learning more generally. Many studies between 1920 and 1960 supported this general view (e.g. Saer, 1923), indicating that bilingualism correlated with lower IQ, cognitive deficiencies and even mental retardation.

It is not a coincidence that most of the above-mentioned research emerged from monolingual societies, particularly the United States and the UK. On the positive side, such research was fuelled by an earnest interest in understanding possible consequences of bilingualism during a period of sharp increase in immigration in these same societies. On the negative side, it was indiscriminately accepted as a result of a political climate that needed to account for immigrant children's scholastic underperformance.

Given what we know about bilingualism 50 years on, it seems inconceivable that the prevailing view once aligned bilingualism with being a burden for general development. Consider the fact that more than $50 \%$ of the world's population found itself then - as it does today-in naturalistic bilingual situations, that is, where more than one language prevails at the societal level. In such environments, bilingualism is the default state. If it were true that bilingualism was harmful for general development, bilingual societies would place their citizens at significant risk relative to monolingual ones. So, the question is how to reconcile the claims from the early 20th-century literature with the fact that bilingualism as a default state has existed for millennia with great success in multilingual societies, in countries such as Luxemburg, Switzerland, India and South Africa.

It was suggested that developmental disadvantages did not apply to bilingualism per se, but rather reflected something about bilingual development outside of bilingual societies. But can it really be the case that bilingualism is either neutral (neither facilitates nor subtracts) or advantageous for development in multilingual societies, while being subtractive in monolingual societies? Although it is true that bilingualism at the societal level has positive consequences for individual bilinguals' language development and ultimate acquisition outcomes, it is not clear how having access to a (significantly) larger bilingual community could ward off the detrimental outcomes said to be caused by the 'confusion' inherent to bilingualism. The task of the bilingual child in and outside of a bilingual country is one and the same. If confusion obtains because of having two languages in a single mind, it applies to all bilingual scenarios. Societies that are themselves bilingual likely provide children with greater quantities and richer qualities of input relative to what bilinguals receive in monolingual societies. We would expect then that environment has much to bear on linguistic development and outcomes, but would not be a potential cause of mental retardation in one extreme and possible cognitive advantages in the other.

Seminal work by Peal and Lambert (1962) effectively changed the way in which bilingualism was viewed. They highlighted how previous studies did not control for deterministic intervening variables that obscured any meaningful conclusions about bilingualism. Prior to this exceedingly few studies imposed careful selection criteria for the inclusion of bilingual participants. Bilinguals with various degrees of proficiency, from various socio-economic statuses, across a range of 
language pairings, with diverse ages of onset and amounts of exposure, were haphazardly grouped together as if none of these variables mattered. To make matters worse, these heterogeneous groups were then compared to homogeneous monolinguals of considerable socioeconomic advantage. Peal and Lambert (1962) imposed meticulous criteria for participant selection and demonstrated that, once deterministic variables were properly controlled, their highly proficient bilinguals were not only equal to, but indeed outperformed appropriately matched monolingual counterparts for both measures of verbal and non-verbal intelligence.

Since the early 1960s virtually nobody has claimed that bilingualism is subtractive in any way, although the effects of bilingualism are still being discussed. According to some researchers, there are no qualitative differences between monolinguals and simultaneous bilinguals in terms of language development (Meisel, 2011). Research has further shown that bilingualism might confer some cognitive advantages to executive functions (e.g. Bialystok, 2009; Bialystok, Craik, \& Luk, 2012). Others argue in favour of limited advantages depending on degree of language usage (Luk \& Bialystok, 2013), but determining the extent of these advantages at present is difficult (Valian, 2015). Whether or not bilingualism results in any cognitive advantages hardly matters; what we know for sure today is that bilingualism is not a 'bad' thing by any measure. Knowing that bilingualism is not 'confusing' to the child is a dramatic change from the past. Yet despite the fact that this has been known for decades within the language sciences, cognitive science and psychology, the traces of injudicious claims made in the early part of the 20th century have not disappeared outside of academia. Today many childcare providers (from medical to educational), government agencies, educational institutions, individual practitioners (teachers, tutors, etc.), parents and more still operate under the idea that bilingualism creates disadvantages. The footprints of previously misguided research still have huge implications for policy and practice related to supporting bilingualism and bi-literacy, offering counsel and advice to parents, maintaining heritage languages, creating language policy and enacting language education.

To be sure, the notion that bilingualism can cause general mental incapability is no longer believed valid within academia. However, the notion that bilingualism, at least under certain conditions, can result in imperfect linguistic acquisition is still very much alive. It is our view that the latter notion is as misguided as the former at the conceptual, theoretical and practical levels. In this article, we will address the notion of so-called incomplete acquisition in the context of heritage language (HL) bilingualism (e.g. Montrul, 2008, 2016). Our position is that incomplete acquisition as a term to describe differences between monolingual controls and heritage speaker (HS) bilinguals is theoretically flawed and misleading, if not unintentionally insensitive. No one denies that the typical endstate grammars of HSs are, on a continuum, different from appropriately matched monolinguals. However, we will argue that different and incomplete, in this domain, are not potential synonyms. Moreover, we will introduce to this general discussion the literature on simultaneous child bilingualism (2L1), which, as a whole, adds a unique perspective and especially strong support against the construct of incomplete acquisition. We focus our discussion on two of several possible causal factors that contribute to variable competence outcomes in adult HSs as compared to monolinguals ${ }^{1}$ : (i) qualitative input factors (e.g. Pascual y Cabo \& Rothman, 2012; Rothman, 2007; Sorace, 2004 ) and (ii) general inaccessibility to formal education/literacy (e.g. Tsimpli, 2014) in the HL. To the extent that we succeed in highlighting the conceptual and theoretical imprecision of the term incomplete acquisition, we will argue that it is time for the field to replace it with more accurate and less potentially evaluative labels that capture not only the description of differences, but inch us towards explanatory adequacy of how and why these differences obtain (as has been attempted in recent years, e.g. Kupisch, 2013; Meisel, 2013; Pascual y Cabo \& Rothman, 2012; Pires \& Rothman, 2009; Putnam \& Sánchez, 2013; Scontras, Fuchs, \& Polinsky, 2015). 


\section{Setting the context: Who are heritage speakers and child bilinguals?}

Given the topic of this article, it seems fitting to first define what we mean by the HS label. Reasonably, one might expect that there is one, unambiguous definition to which all researchers working on HSs ascribe. Under such a scenario, determining which bilinguals qualify as HSs would be straightforward. However, this is not clear in practice. Indeed, all HSs are bilingual by definition, but certainly not all bilinguals are HSs. Agreeing on characterizing parameters for HS-ness is non-trivial, especially because the term heritage speaker itself is relatively new to the field of language acquisition and still does not have ubiquitous use across researchers around the world. The term originated in North America and has over the past two decades been used there increasingly. In the past few years, the term has become more globally used, for example, in Europe and beyond. For researchers primarily interested in formal linguistic issues related to the process, development and ultimate attainment of HL grammars, it is crucial that one makes a difference $a$ priori between those that are naturalistic bilingual acquirers/speakers of an HL and those that are current adult learners of a second language (L2) that is a language of familial heritage. While L2 HL learners, unlike typical novice L2 learners, might have different (higher) motivations, cultural connections, access to (family) native speakers outside the classroom and have had some limited exposure prior to the start of L2 learning, they are not early childhood naturalistic acquirers of the $\mathrm{HL}^{2}$. Therefore, they are not native speakers of the HL in the same way as HS bilinguals (Rothman \& Treffers-Daller, 2014). Interesting to study in their own right as a potential subset of L2 learners, L2 HL learners are different from HS bilinguals. Herein, we follow Rothman's (2009) definition of what an HL is. This definition is relatively uncontroversial, according in several domains with other available definitions (e.g. Benmamoun, Montrul, \& Polinsky, 2013; Montrul, 2008, 2016; Polinsky \& Kagan, 2007), but one crucial difference consists in its purposeful avoidance of the term incomplete acquisition.

A language qualifies as a heritage language if it is a language spoken at home or otherwise readily available to young children, and crucially this language is not a dominant language of the larger (national) society $[\ldots]$ the heritage language is acquired on the basis of an interaction with naturalistic input and whatever in-born linguistic mechanisms are at play in any instance of child language acquisition. Differently [from monolingual acquisition], there is the possibility that quantitative and qualitative differences in heritage language input, influence of the societal majority language and differences in literacy and formal education can result in what on the surface seems to be arrested development of the heritage language or attrition in adult bilingual knowledge (Rothman, 2009, p. 156).

Importantly, this definition differs from others, according to which the HL is a minority language, acquired naturalistically but for a speaker whose first language 'did not develop fully at age-appropriate levels' (e.g. Benmamoun et al., 2013, p. 133, based on Valdés, 2000) or 'often does not reach native-like attainment during adulthood' (Benmamoun et al., 2013, p. 133) ${ }^{3}$. Rothman's definition does not imply anything with regard to potential acquisition outcomes. An HS is a native-speaker bilingual of a minority language spoken at home and either also a native speaker (in the case of 2L1) or a child L2 learner of the majority language of the society in which she/he lives and is educated. Under either scenario, it is virtually inevitable that the HS will wind up being dominant in the societal majority language. However, it seems incongruous to talk about HSs as not reaching 'native-like attainment during adulthood' precisely because they are native speakers by definition. Accepting that HSs are a subset of native speakers (Rothman \& Treffers-Daller, 2014) presupposes that one defines a 'native speaker' with respect to age of onset in a naturalistic context, rather than by some dubious proficiency levels 
that monolinguals supposedly have and/or holding the view that dominance is a necessary deterministic factor. Confusing nativeness with dominance and/or having convergence on a standard monolingual variety as a benchmark only serves to highlight the comparative fallacy of monolingual vs native bilingual comparisons. Such a practice also has serious implications for determining 'nativeness' for subgroups of monolinguals as well as adults who migrate and shift dominance towards an L2 much later in life. HSs do reach native attainment in adulthood because they are native speakers by definition. It may just happen to be the case that the HS native outcomes differ from other sets of natives in ways potentially similar to subgroups of monolinguals with limited exposure and training in the standard language and adult bilinguals under first language (L1) attrition.

A child bilingual (2L1) is typically described as an individual exposed to two languages from birth or very early on in childhood (before three or four years of age, see Meisel, 2011). Research within 2L1 acquisition is often based on longitudinal case studies of developing children between the ages of 18 months and five to six years where children are observed in both languages. This research, which has mostly shown qualitative similarities between 2L1 and monolingual development alongside various degrees of protracted developmental delay or acceleration, has largely been carried out in Western Europe or Canada (e.g. De Houwer, 1990; Hulk \& Müller, 2000; Genesee, Nicoladis, \& Paradis, 1995; Meisel, 1990, 1994a,b; Paradis \& Genesee, 1996, among many others). In contrast, HS research normally looks at acquisition outcomes, it is often based on crosssectional experimental studies with young adults who have been observed only in their minority language. Bringing the trends of available studies together, the picture that emerges shows HSs to be communicatively competent, fluent speakers of their HL. However, HSs display endstate variation in their knowledge and use of the HL that does not normally define other sets of native speakers, specifically monolinguals. Such differences between HL grammars and the monolingual standard can transcend virtually all aspects of the language system, from morphosyntax to phonetics/phonology and especially the lexicon (see Montrul, 2008, 2016). As they are observable and replicated, highlighting such differences should not be controversial. What is apparently contentious is hypothesizing how difference obtains and what it should mean.

To our knowledge, nobody has ever explicitly stated that child 2L1 learners are not HSs - in fact, Benmamoun et al. (2013, p. 133) explicitly include them — and clearly Rothman's (2009) definition would very much include them too. It just so happens that most of the existent research examining HS bilingual competence has examined HS adults (but see Flores, Santos, Marqes, \& Jesus, under review; Montrul \& Potowski, 2007; Pascual y Cabo, 2013; Polinsky, 2011; Rodina \& Westergaard, 2015). This means that much HS research has in fact examined 2L1 acquisition, but at a very different stage of development than the majority of research falling unambiguously under the 2L1 label. Whereas historically the 2L1 literature has focused almost exclusively on developing bilingual grammars in childhood, HS studies have focused on adult endstate grammatical knowledge of either child 2L1 or child L2 speakers. The relevance of highlighting this is at least two-fold. First, we wish to bring to the attention of researchers who work on child bilingualism the idea that HSs are simply the adult outcome versions of the children they typically study. Second, we wish to highlight how bringing what is known from the child bilingualism literature into the domain of HS studies raises serious questions about claims made in the adult HS literature. We take it as a given that $2 \mathrm{~L} 1$ children who grow up outside bilingual communities are HS bilinguals. The main difference between these two groups is terminological and differentiated primarily by age.

To the extent that it is fair to conceive of child 2L1ers as a subtype of HSs, the fact that the majority of $2 \mathrm{~L} 1$ research concludes that $2 \mathrm{~L} 1$ development is not qualitatively different from monolinguals' complicates the observation of ubiquitous qualitative differences in the endstate grammars of HSs compared to monolinguals. By bringing the 2L1 literature to bear on HS theoretical 
epistemology, we hope to highlight that the explanation for differences in HS outcomes requires more than conjecture about specifically what happens between the timeframe of six to eight years and young adulthood, the former being the age 2L1 studies usually stop and the latter the age where HS studies typically pick up.

\section{Studies of 'successful' heritage speakers}

In this section, we summarize studies of adult HSs in Germany, comparing two populations, HSs of Italian and HSs of French. The latter perform monolingual-like, in spite of their variable and quantitatively reduced input throughout the lifespan. The eight studies reported were all carried out as part of the project E11 at the Research Centre of Multilingualism in Hamburg, precisely where in the late 1980s and 1990s many of the early systematic studies with 2L1 children were carried out, based on projects such as Deutsch und Französisch-Doppelter Erstspracherwerb (DUFDE), Baskisch und Deutsch-Doppelter Erstspracherwerb and others (see Schmidt \& Wörner, 2012, for an overview). The aforementioned projects traced 2L1 bilinguals in their two languages over several years, finding evidence for separate language development and qualitative similarities with monolingual children, especially in morphosyntax (see De Houwer, 1995, for an overview). More than two decades later, E11 looked at equivalent populations (German-French, German-Italian), but this time during adulthood. In what follows, we examine the motivation behind the selection of participants in E11, then summarize a number of studies.

The research in E11 stands out among HS studies in restricting the data collection to bilinguals with simultaneous exposure to two languages from birth. This is most easily guaranteed in speakers who grew up in binational families, where parents have different native languages which they consistently use with their children. The reason for including only bilinguals with exposure to both languages from birth was to exclude age of onset (AoO) in the majority language as a potential confound. Now how is AoO in the majority language relevant to the acquisition of the HL, which is acquired from birth? With simultaneous exposure from birth HL and majority language are always in contact, including during the very early years, which are generally deemed to be crucial for language acquisition. In the case of successive acquisition, i.e. when AoO in the HL precedes AoO in the majority language, the HL has more time to develop independently. Thus, the acquisition of some phenomena in the HL may already be completed before exposure to the majority language begins. In this respect, simultaneous bilinguals from birth might be seen as facing the hardest task, since their HL evolves under the potential influence of the majority language at all times. There is indeed evidence that the earlier presence of the majority language at home (e.g. through mixed marriages) may have a negative impact on the development of certain domains of the HL (see Rodina \& Westergaard, 2015, for children and Van Suchtelen, 2014, for adult HS), suggesting that the two populations, simultaneous and sequential bilinguals, should be studied separately.

Moreover, E11 used predominantly bilingual rather than monolingual controls. For example, instead of comparing French/Italian HSs to French/Italian monolinguals, the controls were HSs of German from France/Italy who had acquired French/Italian and German from birth, i.e. the mirror image of French/Italian HSs in Germany. Majority-language speaking bilinguals are better controls than monolinguals because the (same) two languages are always in contact during acquisition, so that the possibility of mutual language influence is constantly given. Moreover, they have the same AoO in their two languages, and are thus preferable to L2 learners with the same language combinations, who often served as groups of comparison in previous research (e.g. Montrul, 2008). Coincidentally, most bilingual speakers participating in the studies also had high school degrees (corresponding to German 'Abitur'). 
In summary, E11 investigated relatively homogeneous populations: bilinguals with the same $\mathrm{AoO}$ in their two languages and a relatively high socio-economic status. In anticipation of the studies summarized below, it is worth noticing that most participants in the German-French group even attended the same school, where the HL was not the target of instruction but the medium.

The target phenomena were gender marking, adjective placement, determiner use in generic expressions and voice onset time. All phenomena are sufficiently different between French/Italian and German, so that cross-linguistic influence (CLI) is likely to occur. In fact, all these phenomena had been studied previously in developing bilinguals and were shown to be vulnerable to CLI.

\section{Heritage speakers of French attending French schools in Germany}

Most speakers who eventually took part in the study, coincidentally, had attended the Lycée Français de Hambourg, a school that is part of a network of Francophone schools outside of France that follow the curriculum of the French ministry of education. Besides French, the school attempts to integrate German language and culture and allows for the simultaneous attainment of the French Baccalauréat and the German Abitur ('Abibac'), facilitating university access in both countries. Despite attending this school, most of the participants felt more at ease using German than using French and it was typical for them to speak German outside school, e.g. even when talking to each other in the school yard.

The first study (Kupisch, Akpinar, \& Stöhr, 2013) was concerned with the acquisition of gender in French. Gender is an early acquired property in German-French bilinguals, with children choosing articles correctly in more than $90 \%$ of all contexts by the age of three. The acquisition of gender may be protracted in unbalanced bilinguals but generally follows the patterns of monolingual development in qualitative terms, i.e. regarding the type of errors made. German and French both have grammatical gender, but German has one additional gender and gender assignment and agreement patterns differ across the languages, creating a high potential for errors and CLI. The speakers were tested via an acceptability judgment task (AJT) and in elicited production. In both cases, particularly challenging conditions were included, e.g. gender agreement with adjectives whose equivalents in German are not gender marked, or nouns representing conflicting gender assignment rules, e.g. the noun sentinelle 'nightguard' was contextualized as a man despite being grammatically feminine (the ending - elle is associated with feminine gender). Results showed successful assignment and agreement with over $95 \%$ accuracy. Minor disadvantages were observed in gender assignment as compared to agreement, especially with nouns that are infrequent and/or represent conflicting assignment rules. This seems to indicate disadvantages with linguistic information that has to be memorized (i.e. intrinsic lexical information that cannot be derived from any productive rule) as compared to rule-based linguistic knowledge, as relevant for syntactic gender agreement and rule-based gender assignment.

The second study (Kupisch et al., 2014), was concerned with adjective placement. In this domain too, French differs from German in having two possible positions for adjectives. Some adjectives can be used in both positions, often with a difference in meaning (un grand homme 'a famous man' vs un homme grand 'a tall man'). German, like English, only has prenominal adjectives. It is known that simultaneously bilingual children acquiring a Romance language and a Germanic language use both positions from early on but often overuse the prenominal position, which is present in both languages, especially if their Germanic language is dominant. The speakers in Kupisch et al. (2014) were tested via an AJT, again, including particularly challenging conditions. For some items, only the context gave a clue to the correct adjective position; in other cases, the adjective was part of a fixed expression and its position could not be derived by any rule or 
even contradicted existing rules. On average, participants performed with $90 \%$ accuracy. Speakers were highly accurate when the position of the adjective was dependent on contextual information. By contrast, fixed expressions were relatively error prone. Cases of incorrect use mostly resulted in overusing postnominal adjectives. The results of this study too suggest that when proficient bilinguals perform differently from monolinguals, this may be due to lexical gaps rather than CLI from the dominant language.

The third study was concerned with the use of articles in generic plural determiner phrases (DPs, Barton, 2015). Generic DPs generalize over a class of individuals or objects, e.g. Sunflowers are yellow. In French, these must be formed with a definite article, while the absence of the article leads to ungrammaticality (see 1(a)). In German, article use is optional (see 1(b)).

1. (a) Fr. *(Les) tournesols sont jaunes.

(b) Ge. (Die) Sonnenblumen sind gelb the sunflowers are yellow 'Sunflowers are yellow.'

Crucially, bare nominals are ungrammatical in French, while being the standard norm in German. As with adjective placement, the languages overlap partially, but this time it is French that allows only one type of syntactic structure (article+noun), while German allows two structures (article+noun, bare noun). As for their semantics, definite marked French DPs are ambiguous between generic reference and reference to a specific set of individuals or objects. For instance, Les chats sont intelligents (literally, the cats are intelligent) can refer to cats in general or a specific group of cats. German, like English, disambiguates between the two readings by using bare nouns; e.g. Cats (in general) are smart vs The cats (we just saw) are smart, although, as mentioned before, in some varieties of German the definite article is used for generic reference as well. Barton (2015) studied acceptance of bare nominals in French under the potential influence of German. In an AJT, bilingual French speakers rejected bare nouns more than $90 \%$ of the time. Furthermore, in a truth value judgment task which assessed the preferred reading of definite plural nominals (e.g. French Les tournesols sont jaunes, German Die Sonnenblumen sind gelb), the bilinguals preferred a generic reading in French and a specific reading in German. In summary, the HSs of French performed on par with monolingual speakers in accepting and interpreting plural subject nominals. With respect to this phenomenon, the result is particularly remarkable since previous studies have reported late acquisition and CLI for developing bilinguals acquiring a Germanic and a Romance language (Kupisch \& Pierantozzi, 2010; Serratrice, Sorace, Filiaci, \& Baldo, 2009) and incomplete acquisition in adults (Montrul \& Ionin, 2012).

The fourth study (Lein, Kupisch \& van de Weijer, 2016) looked at voice onset time (VOT). VOT is the most salient cue differentiating language-specific realizations of voiced (/b, d, g/) and voiceless $(/ \mathrm{p}, \mathrm{t}, \mathrm{k} /)$ plosives. It refers to the interval between the release of the stop and the onset of voicing. In French and German, voiced and voiceless stops are associated with different types of VOT. Lein et al.'s study focussed on voiceless $/ \mathrm{k} /$, which in French exhibits a short voicing lag (VOTs ranging between 30-50 milliseconds (ms) across studies) and in German a long voicing lag (VOTs ranging between 35-80 ms across studies). Thus, German voiceless stops have longer VOTs than French ones. In acquisition, short lag is comparatively unproblematic and acquired early while long lag time is relatively more marked. Early bilingual children acquiring languages with different VOT realizations may show delayed acquisition of target values (Kehoe, Lleó, \& Rakow, 2004). Lein et al. investigated VOT productions of seven HSs in spontaneous conversations of 20-30 minutes. Their French VOTs were compared to those of French-dominant bilinguals from France as well as their VOT productions when speaking German. Their average VOTs in French were $37.2 \mathrm{~ms}$ long, compared to $35.6 \mathrm{~ms}$ in French-dominant bilinguals from France. The difference was not significant. Furthermore, 
Table I. Comparison of studies with French HSs and Italian HSs, correctness scores and average VOTs (data from Bianchi, 20I3; Kupisch 20I2, 20I4).

\begin{tabular}{llllll}
\hline & $\begin{array}{l}\text { Gender } \\
\text { assignment }\end{array}$ & $\begin{array}{l}\text { Gender } \\
\text { agreement }\end{array}$ & $\begin{array}{l}\text { Adjective } \\
\text { placement }\end{array}$ & $\begin{array}{l}\text { Article use with } \\
\text { generic DPs }\end{array}$ & VOT \\
\hline French HSs & $93.2 \%$ & $95 \%$ & $90.1 \%$ & $90.5 \%$ & $37.2 \mathrm{~ms}$ (within monolingual range) \\
Italian HSs & $79.7 \%$ & $92.8 \%$ & $82.6 \%$ & $33 \%$ & $43.8 \mathrm{~ms}$ (within monolingual range) \\
\hline
\end{tabular}

DP: determiner phrase; HS: heritage speaker; VOT: voice onset time.

all HSs had clearly distinct VOT ranges in their two languages (mean for German $50.8 \mathrm{~ms}$ ). Overall, the HSs performed within the range of monolinguals and did not differ significantly from their bilingual controls who spoke German as their HL and French as their dominant language.

\section{Comparison with heritage speakers of Italian attending German schools in Germany}

The same four domains that were studied in the French bilingual group were also investigated with the Italian HSs introduced above. The same methodology was used, albeit with minor modifications. ${ }^{4}$ With respect to the target phenomena, Italian and German display the same differences as French and German. The bilinguals in this group had all attended monolingual German schools. However, some of them had attended weekly HL instruction classes during their childhood, where they practised reading and writing Italian. At the time of testing, some were in the process of studying Italian at university, or studied or worked in Italy. The group also included participants who did not use Italian regularly after starting primary school. Although all participants could read and write in Italian, they did not necessarily use these skills on a regular basis.

To anticipate the results, the Italian HSs differed more from monolingual norms than their French counterparts in each of the phenomena. Average scores (percentage of monolingual-like answers) are reported in Table 1.

For grammatical gender, there were two experiments, an elicited production task and an AJT (Table 1 shows the combined percentage of correct use). Similar to the French HSs, the Italian HS were better at marking agreement than at assigning the correct gender to the noun. However, the gap between the success rates in agreement vs assignment is larger compared to the French HSs, suggesting that there was a higher number of nouns the participants were not sufficiently familiar with. ${ }^{5}$

Adjective placement was tested by means of an AJT. The difference in results between the French and the Italian HSs is comparatively less pronounced here. In the Italian experiment, problems mostly occurred with adjectives whose meanings varied depending on the position. Again, it was typical for speakers to overuse the postnominal position, i.e. the default and more frequent position for Romance adjectives.

The study on article use with generic plural subjects showed the largest contrast between the French and the Italian HSs. Correcting bare nouns into nouns with definite articles turned out to be particularly difficult for the Italian HSs with correctness scores as low as $33 \%$. When it came to spontaneous interpretations of definite marked plural subjects in a truth value judgments task, Italian HSs preferred the generic interpretation, as: is also typical for monolingual speakers.

The VOT study also focused on the production of the voiceless stop $/ \mathrm{k} /$ in naturalistic speech. Italian is similar to French in that $/ \mathrm{k} /$ is produced with a short lag. The Italian HS produced average VOTs of $43.8 \mathrm{~ms}$ (compared to the $36.5 \mathrm{~ms}$ produced by the Italian-dominant bilingual 
controls from Italy). In other words, the HSs' VOT were comparatively more 'German-like', though still within the limits of what has been reported for Italian monolinguals (38.4 ms). The Italian HSs produced significantly longer VOTs in German $(59.3 \mathrm{~ms})$, suggesting language separation similar to the French HSs, but a stronger tendency to produce longer, i.e. more Germanlike, VOTs in their HL.

\section{Summary}

Four studies were carried out with French and Italian HSs in Germany, testing the same phenomena with the same methodology. The French HSs had attended French schools during their childhood, while the Italian HSs had attended German schools. Overall, the French HSs outperformed the Italian HSs. At the same time, the two groups appeared to face qualitatively similar problems. For instance, difficulties were more apparent when lexical knowledge was required (e.g. gender assignment) than in the application of grammatical rules (e.g. gender agreement). Moreover, both groups showed clear evidence of language separation. For instance, in the study on adjective placement, HSs overused the postnominal position, which is typical for and unique to their Romance languages, rather than the prenominal position that is common to both languages. Similarly, VOT realizations occurred in clearly distinct ranges in the speakers' two languages.

The explanation for the French HSs' advantage may be that they had attended French schools continuously for more than 10 years. They were familiarized with the standard (academic) register and French literature from an early age, and they had experience taking exams and language tests in French. They were thus familiar with formal registers of French, a broader range of lexical domains and task-taking procedures. Some of the Italian HSs were also formally instructed in Italian. However, their experience did not provide them with the same type of linguistic experience that the French HSs had accumulated during their earlier years. Taken together, the data sets emerging from the E11 project lend support to Rothman's $(2009$, p. 156) claim that “... differences in literacy and formal education can result in what on the surface seems to be arrested development...". Our point is definitively not that education is necessary for bilinguals to converge more closely on domains of grammar that are more standard-like, but that consistent educational contexts provide them with quantitatively and qualitatively more opportunities to do so. By extension then, the absence of this might explain some differences that obtain when schooling is not provided in the HL.

\section{Discussion}

\section{The term 'incomplete acquisition'}

What does 'incomplete' mean? In our view, it should mean that a grammar is somehow unable to fulfil the remit of language because it lacks properties that govern the constitution of natural language, as some have argued for adult L2 acquisition (see Schachter, 1990, and his Incompleteness Hypothesis), or is not sufficiently developed as a system to reliably encode and decode all necessary linguistic information (as might be the case of pidgeons). This is clearly not the case of HS grammars. In our view, naturalistically acquired native grammars that are sufficiently developed for communication cannot be incomplete, only different - potentially drastically-from one another by comparison. HSs are native speakers of their HL. The fact that they often differ from monolinguals is interesting and potentially revealing for theoretical questions (see Benmamoun et al., 2013), but difference from an arbitrary standard does not suggest that said system is incomplete.

Linguistic completeness of any grammar, heritage or otherwise, cannot be determined by comparison to another grammar. For example, we do not argue that English is incomplete compared to German because the former no longer has morphological case inflections. But it is still relevant to 
discuss in the present context. The main difference as it relates to this being a standard practice in HS studies is, in our view, one of not properly managing expectations. In the case of the EnglishGerman comparison, no one expects speakers exposed to English to wind up with a system that has morphological case outside of the pronominal system. Of course, English is not incomplete in comparison to German. They are just different, in much the same way as are apples and oranges. But is it fair to expect HSs to wind up with grammars like native monolinguals? If not, then they too are apples and oranges, or at least different species of apples. The comparison is equally unjust. Fortunately, linguistic theory affords us the possibility of avoiding this. Defining completeness on the basis of whether grammars abide by the universal rules of natural language formation and being sufficiently developed for communicative purposes avoids potential pitfalls and should be the only criterion for determining if a language is complete. If so, then HS grammars are complete, full stop.

The state of linguistic science at any particular moment in time has no obligation to be right. In fact, the humble goal of science is merely to be increasingly more accurate over time. History has proven most reasonable theories, hypotheses and constructs to be flawed, at least to some degree. Determining incorrectness, however, is only possible in the first place on the coattails of highquality proposals and only after they have had sufficient impact on a field. Arguing against a preceding proposal is likely the highest testament to its importance and effectiveness in pushing any field forward. Although science can never be assured to be right, it should be as descriptively and explanatorily precise as possible. This obligation entails accepting a priori that specific proposals will be wrong most of the time. The construct of incomplete acquisition is a case in point. The pioneering work done by several researchers who assume this construct is not to be understated. To be sure, our argument is not with the empirical basis that shows differences between HSs and monolingual controls, but solely with the precision of the term incomplete acquisition. As we outlined in the introduction, the history of studying bilingualism over the past 100 years shows that terminology matters a great deal. Once offered to the public domain, terminology can have farreaching and long-lasting effects, even — perhaps especially_when these are unintended by their original promoters. Once the ink dries on the words we put to paper, we no longer control how others interpret and use them. It seems illogical to believe that (many/most) scientists in the early part of the 20th century had any ill intention in using inaccurate and inconsiderate labels to describe bilingualism. Nevertheless, some 50 years later these ill-fated labels still echo. From time to time then, it is useful to review the terms we use, especially when such terms relate to real groups of people and can influence policies that affect them.

Potentially inaccurate terminology does not always matter to the same degree. When debating terminological minutiae that has little potential impact, there is no need to enter into arguments. However, where there is potential for impact - at the level of science and beyond - it is worth forcing debates. Although most scientists are principally concerned with the task of doing good science, we also have a commitment to the communities we engage with-scientific peers, our participants and the public we aim to serve via our research. In this light, we submit that the time has come to do away with the term incomplete acquisition. Although we have shown exceptions, no one denies that HS grammars are often significantly different from monolingual ones. So, why are we suggesting the term incomplete acquisition is universally inaccurate? The short answer to this question is because the term is theoretically flawed and potentially harmful.

\section{Differences between developing $2 \mathrm{~L} / \mathrm{s}$ and endstate HSs in Europe and North America?}

We have pointed out that many HS studies that label their acquisition outcome as 'incomplete' have emerged from the US, while many studies reporting monolingual-like acquisition in 
early developing bilinguals have emerged in Europe. These differences may have various explanations:

(i) The conditions for bilingualism vary across countries and continents;

(ii) Studies on early bilinguals often focused on 'elite bilinguals', while studies on adult HSs often focused on stigmatized populations;

(iii) Studies on early developing bilinguals were often based on naturalistic speech (where potentially problematic structures can be avoided) and studies on adults HSs on experimental data (where potentially problematic structures are often explicitly targeted);

(iv) Early bilinguals might have been studied 'too early', i.e. before their development could have been 'arrested' or 'attrited'.

The motivation for carrying out the research summarized in section 3 was to look at a European population of adults comparable to previous studies on developing $2 \mathrm{~L} 1 \mathrm{~s}$, but using endstate data. The comparison of the two groups of HSs (French/Italian) in this paper shows that there is nothing special about bilingually educated European HSs. With respect to similar tasks and phenomena, some HSs behave like monolinguals, others don't. For example, the Italian HSs had noticeable problems using articles with generic DPs, thus performing very similar to Spanish HSs in the US on comparable tasks (e.g. Montrul \& Ionin, 2012). By contrast, the French HSs, who developed their French under similar conditions as monolinguals, with all the extra high quality input that formal schooling provides, behaved like monolinguals. It follows that the lack of formal education in the HL could be the primary explanation for HS/monolingual differences.

\section{Formal education: Why it matters and what for}

The results reported in section 3 suggest that diverging trajectories in language input and output, including additional training of the native language, spoken and written, in a formal context is precisely what distinguishes monolingual and multilingual speakers, as well as multilingual speakers with different proficiencies. Since formal training happens between later childhood and early adulthood, it may explain the ubiquitous differences between monolinguals and HSs noted in the literature. Previous studies on school-aged heritage bilinguals are in line with this conclusion. Relevant examples are Montrul and Potowski's (2007) study of six- to eleven-year-old EnglishSpanish children in Chicago and Kupisch and Pierantozzi's (2010) study of six- to eleven-year-old German-Italian children in Hamburg. The children in both studies attended dual immersion schools, which combine minority language-speaking children with majority language-speaking children in the same classrooms and provide some of the teaching through the minority language. In both studies, the heritage bilinguals performed differently from monolinguals, i.e. Spanish and Italian monolinguals, but in neither study was there a decline in linguistic abilities with increased age, suggesting that schooling of the HL can prevent language loss in such contexts. However, both studies left open whether schooling has long-lasting effects (beyond school) and how much schooling is necessary to attain monolingual-like competence. In a somewhat different context, Bylund and Diaz (2012) investigated the effects of HL classes (once per week) on first language proficiency in HSs of Spanish in Sweden in 12th grade. The results showed that HSs who attended HL classes at the time of testing performed better on grammaticality judgments tasks (GJTs) and cloze tests than HSs who did not attend any classes at the time of testing. However, the latter group had attended HL classes before, and the two groups did not differ with regard to total HS class experience, suggesting that once attendance to HL classes stops, its positive effects on L1 proficiency 
become less obvious (p. 605). The authors raise the question of the extent to which their findings are generalizable to HS populations in other contexts of HL education and testing formats where literacy skills are less relevant than in GJTs and cloze tests. The studies reviewed in section 3 seem to provide us with a tentative answer:

There are (at least) three different dimensions in which schooling might explain differences between monolinguals and bilinguals. The most obvious dimension concerns properties of the standard language that are typically considered to be indicators of sophisticated language, elaborate style and/or register, e.g. subjunctive in German, or French liaison. Such phenomena are, often taught to monolingual speakers at school, though not necessarily mastered after instruction. Other examples include the genitive case in German, clitic object pronouns in some Romance languages and the inflected infinitive in Brazilian Portuguese, which are subject to regional and diastratic variation. Obviously, speakers with exposure to regional varieties but without additional exposure to the standard variety at school, have fewer chances of acquiring these properties (Pires \& Rothman, 2009).

A second dimension in which formal schooling in the HL might foster HL maintenance is in having the HL not as the object of learning but as the medium of instruction, because learners will be familiarized and learn how to deal with scholarly instructions in this language. Anecdotally, HSs often report having problems understanding instructions when taking part in experiments, while the very same instructions seem to be clear to most L2 learners.

A third dimension regards aspects of language that are not explicitly taught in heritage or foreign language classes, but that are nevertheless (positively) affected by language exposure at school. Bylund and Diaz (2012, p. 305) ask whether HL class attendance has its strongest effects on written and more metalinguistic modalities of L1 proficiency as compared to more automatic and implicit L1 knowledge, or whether other modalities are positively affected too. The studies reported in section 3 suggest that formal instruction will also affect non-instructed, implicit linguistic knowledge, since the phenomena discussed there are typically not part of native or foreign language instruction. So, why should there be beneficial effects? Schooling involves working with texts whose grammar and lexicon go beyond colloquial language, e.g. classic literature or texts in formal, technical or scientific language. Thus, learners are automatically exposed to a wider range of grammatical constructions and vocabulary items, even if these are not explicitly addressed. Furthermore, the language spoken by teachers in dual immersion classes is likely to sound different from the language that HSs hear at home, being mostly closer to the standard variety. Of course, dialect speakers too may have their first contact with the standard variety when they go to school, but they differ from HSs in having the opportunity to hear their majority language outside of the school setting. Finally, formal school settings provides significantly more opportunity to use the language and its different registers more authentically with a greater variety of people, especially peers of the same age.

So why was formal training in our studies more beneficial for the French bilinguals than for the Italian bilinguals? One major difference between the two groups was that the French HSs had French as the medium of instruction and exposure (in a school setting) every day with input from various speakers. The Italian HSs, by contrast, (those who attended HL classes) had Italian as the target of instruction, only once per week (if at all) and often by only one single teacher. This suggests that in order for schooling to have long-terms beneficial effects (in morphosyntax, lexicon and pronunciation), input needs to be continuous and come from a variety of different native speakers. Evidence of this type suggests that dual-language bilingual education has benefits to language development that is retained in adulthood.

Another difference between the two groups of bilinguals is that Italian HSs in Germany are typically exposed to first generation speakers from different regions in Italy, who often communicate 
amongst each other in a neutral regional variety (if not in German). By contrast, speakers of French (at least in Europe) have a stronger inclination to convergence on the alleged standard language. In addition, the two groups tend to have different attitudes towards language norms. Italian dialects are very much alive today and speakers are somewhat more tolerant towards variation. This means that it might be less important for an Italian HS to sound like a monolingual speaker of the standard language.

A final question to ask at this point is whether French or Italian were acquired at the expense of linguistic abilities in German. The answer is simple. The bilingual populations who participated in the aforementioned studies were also investigated in their dominant language, i.e. German. None of the studies reported any differences from monolingual-like, standard German norms (see Barton, 2015 on generic nominals for an example).

\section{Comparison with monolinguals}

HSs often - but not always - have significantly less input in the HL than a monolingual speaker of the same language. Their input is often qualitatively different, they tend to lack formal literacy training, and they use the language in fewer contexts than monolinguals. Furthermore, unlike monolinguals, HSs have another (usually dominant) language that can exercise some influence on the HL. So, why should we expect them to wind up sounding like monolinguals? If the potential for convergence with monolingual systems is unlikely from the start, how can we call bilinguals incomplete for not having achieved something they are unlikely to achieve in the first place? Apparently, as we saw in our review of several studies in the previous section, when some contributing variables are nullified across HSs and monolinguals, such as an education in the HL during early childhood, differences seem to disappear. This adds support to our general position. By extension, this suggests that being a less monolingual-like HSs is more a reflection of not having had the same opportunity to be convergent. The HS grammar is not incomplete, it is just complete and different as a matter of circumstance.

Differences between early bilinguals and monolinguals have been discussed in terms of being quantitative or qualitative. These debates have been more intensive in research on developing bilinguals than in research on adult HSs. Learners count as qualitatively different from monolinguals if they commit errors that are typical for adult L2ers but never observed with monolinguals, or if they acquire certain properties in a different order than monolingual children. By contrast, accelerated or delayed acquisition with respect to monolinguals are seen as quantitative differences.

For a long time, a predominant view was that the syntactic development of early bilinguals is similar to that of monolinguals (e.g. Meisel, 2011; Paradis \& Genesee, 1996), provided that AoO happens below a certain age. Over time, diverging opinions have emerged, with some scholars arguing that the weaker language of a bilingual can have L2-like features and thereby be qualitatively different from (monolingual) L1 development (Schlyter \& Håkansson, 1994). Further, there is no agreement on what counts as a quantitative or qualitative difference. While qualitative differences have become a matter of debate for syntacticians, phonologist have already accumulated evidence that the simultaneous development of two phonological systems can be qualitatively different from those of monolinguals, e.g. resulting in inverted acquisition orders due to CLI (see Kehoe, 2015; Lleó \& Cortés, 2013). Given the undeniable existence of extreme inter-individual differences across HSs, it will be hard to maintain the original view that differences between early bilinguals/HSs and monolinguals are merely quantitative in nature. Clearly, there are factors beyond AoO that determine acquisition outcomes. What matters is not whether the emerging or final systems are different-we know they often are-but how they are different and under what circumstances. 
Finally, we wish to point out how HL acquisition, as compared to monolingual acquisition, might relate to language change. For instance, English once had morphological case in the nominal domain, like present day German. Over many generations this changed, presumably because the language of the generation before was not taken up exactly the same way by the subsequent generation (e.g. Lightfoot \& Westergaard, 2007). The idea is that HS grammars might simply show us how quickly language change can take place in bilingual contexts with less than optimal support for the development and maintenance of HLs. The difference between significant grammatical language change over many generations and the accelerated case of individual HS grammars might have more to do with context than anything else. In the typical case of language change, the changing language is the dominant societal language. In the case of HSs, we are looking at change to the minority one. The fact that HS grammars at the individual level exist on a continuum, meaning some are more monolingual-like than others, is likely a mere reflection at the individual level of the potential each HS had to become monolingual-like. Related to what we discussed in 4.1. above, one difference between HL research in the US and HL research in Europe might be that the former often focuses on large minority communities with comparatively low prestige, whereas many studies of early bilinguals in Europe have looked at comparatively smaller communities and more prestigious languages (Romance languages in Germany, for instance). This may also play a role in explaining the different results in the two types of research traditions: in large communities with much contact among its members, we might be dealing with language change on a bigger scale, whereas in small communities differences are more likely to occur at the individual level.

\section{Conclusions}

We hope to have given sufficient context regarding why we consider the term incomplete acquisition to be theoretically and descriptively flawed and inadvertently insensitive. If we are on the right track, then the term should be replaced without further consideration. Calling a bilingual's grammar incomplete because it fails to meet an unattainable threshold of comparative similarity to a different group of native speakers unwittingly perpetuates the notion that bilingualism results in imperfect language acquisition of either one or even both languages. Although this most certainly is not the message intended by linguists who use this term, it is often what is understood by nonlinguists who access such work but do not have the training to understand the nuances of what is meant. Of course, the standard meaning of 'incomplete' assumes the potential of completion, so understood without proper context it is reasonable to deduce that incomplete acquisition entails that bilingualism, at least in a HL context, results in imperfect acquisition. In addition to being misleading, the term unwittingly privileges monolingualism and perpetuates it as the 'should-be default state'. It could also give the impression that there is something wrong with HS grammars; something that we should endeavour to fix. Of course, HSs are not broken and education in the standard variety is not meant to fix them, but rather provide them with an opportunity to acquire different registers of their HL that will happen to be closer to what monolinguals speak. Confronting myths related to bilingualism has been an uphill battle for the larger part of a century. Insofar as terminology matters, researchers have an obligation to use accurate terminology that cannot be misinterpreted or potentially harmful to individuals. We cannot imagine that any HS appreciates being told that their grammars are incomplete, although we can imagine that they would hardly mind knowing the non-evaluative reality that their grammars are different from monolinguals.

In summary, there are no good reasons for calling heritage speaker grammars 'incomplete' because (i) not all heritage grammars are different from monolinguals and (ii) the reasons for deviance from monolinguals can be manifold, including issues related to quantity and quality of input and access to literacy training, which all apply to monolinguals as well. That a similar degree of 
inter-individual variation is not usually seen across monolinguals is likely to be due to two facts. First, the typical monolingual controls are formally educated in that language; when not, there are often significant differences (see Dabrowska, 2012). Second, monolinguals almost always grow up within a majority language context and their L1 is the majority language or a mutually intelligible dialect of the majority language.

Since we have suggested that the term incomplete acquisition is inappropriate to describe any outcome of naturalistic acquisition - bilingual or otherwise - it seems appropriate to offer some alternative terms that capture the differences between monolingual and HS grammars. We submit that differential acquisition is a more appropriate term. The word differential captures the reference to difference compared to monolinguals as well as degrees of difference across individual HSs. Future research that is designed specifically to tease apart the contributing variables that make many HS grammars different from monolingual ones will be well served to consider the epistemological discussion offered in this paper.

At a minimum, this discussion underscores the complexity of the HS situation. It underscores the need to expand the empirical basis of the research we do, for example, replacing monolingual controls with appropriate bilingual ones, undertaking pseudo and actual longitudinal data, getting fine-grained background information and running correlations with input factors. In our view, doing this will make HS research more ecologically valid. It will bring us beyond the current state of describing HS differences towards actual explanation of how and why differences emerge without resorting to backward assumptions regarding the path of development based solely on endstate experimental data. It will also foster the need to explain the composition of HS grammars in their own right, under a view that accepts them as complete entities worthy of formal description.

\section{Acknowledgements}

We wish to thank the audiences at ISB10 at Rutgers University at the Cambridge Romance Seminars; Miriam Geiss, Cristina Flores, Anika Lloyd-Smith and two anonymous reviewers for commenting on earlier versions of this paper. Many thanks to Aafke Hulk and Suzanne Aalberse for initiating this timely discussion of research on heritage and early bilinguals, and for giving us the opportunity to present our views.

\section{Declaration of Conflicting Interests}

The author(s) declared no potential conflicts of interest with respect to the research, authorship, and/or publication of this article.

\section{Funding}

The author(s) received no financial support for the research, authorship, and/or publication of this article.

\section{Notes}

1. When referring to 'monolinguals' we mean speakers who grew up in homes where only the majority language was spoken and who attended monolinguals schools in the majority language.

2. It is possible, even likely depending on the HL, that HSs (as defined here) enroll as adults in language classes, either studying their HL in foreign language - alongside L2 HLs (as defined here) and novice L2 learners - or in classes specifically designed for HSs. In such cases, HSs are exposed to the standard variety of the HL, which may even be considered a specific case of third language acquisition (see Polinsky, 2015).

3. Benmamoun et al. (2013) explicitly state that with reference to heritage speakers, 'non native-like' is equivalent to 'different' rather than 'incomplete' (p. 167, FN 14). In other publications, however, the term 'incomplete' is used with reference to heritage speakers (e.g. Montrul, 2008).

4. These minor differences concerned the following aspects: (i) The control sentences were not exactly the same in the two languages. (ii) The Italian study on gender tested particle agreement rather than adjective 
agreement. (iii) The number of participants was not exactly the same in all Italian studies because we started to publish first results while additional data was still being collected. (iv) Not all data were suitable for acoustic analyses in the VOT study.

5. The nouns providing difficulties in assignment typically contradicted the general assignment rules of Italian, e.g. il copra ('the copra'), a noun which carries masculine gender although ending in - a, i.e. a consonant normally associated with feminine gender.

\section{References}

Barton, D. (2015). Generische Nominalphrasen bei deutsch-französischer Zweisprachigkeit. PhD Dissertation, University of Hamburg.

Benmamoun, E., Montrul, S., \& Polinsky, M. (2013). Heritage languages and their speakers: Opportunities and challenges for linguistics. Theoretical Linguistics, 39(3/4), 129-181.

Bialystok, E. (2009). Bilingualism: The good, the bad, and the indifferent. Bilingualism: Language and Cognition, 12, 3-11.

Bialystok, E., Craik, F. I. M., \& Luk, G. (2012). Bilingualism: Consequences for mind and brain. Trends in Cognitive Sciences, 16, 240-250.

Bianchi, G. (2013). Gender in Italian-German bilinguals: A comparison with German L2 learners of Italian. Bilingualism: Language and Cognition, 16(3), 538-557.

Bylund, E., \& Díaz, M. (2012). The effects of heritage language instruction on first language proficiency. A psycholinguistic perspective. International Journal of Bilingual Education and Bilingualism, 5, 593609.

Dabrowska, E. (2012). Different speakers, different grammars: Individual differences in native language attainment. Linguistic Approaches to Bilingualism, 2, 219-253.

De Houwer, A. (1990). The acquisition of two languages from birth: A case study. Cambridge, UK: Cambridge University Press.

De Houwer, A. (1995). Bilingual lLanguage acquisition. In P. Fletcher, \& B. MacWhinney (Eds.), The handbook of child language (pp. 219-250). Oxford, UK: Blackwell.

Flores, C., Santos, A. L., Marqes, R., \& Jesus, A (under review). Age and input effects in the acquisition of mood in Heritage Portuguese. Journal of Child Language.

Genesee, F., Nicoladis, E., \& Paradis, J. (1995). Language differentiation in early bilingual development. Journal of Child Language, 22, 611-631.

Hulk, A., \& Müller, N. (2000). Crosslinguistic influence at the interface between syntax and pragmatics. Bilingualism: Language and Cognition, 3(3), 227-244.

Kehoe, M. (2015). Cross-linguistic interaction: A retrospective and prospective view. In E. Babatsouli, \& D. Ingram (Eds.), Proceedings of the international symposium on monolingual and bilingual speech 2015 (pp. 141-167). URL: http://ismbs.eu/publications

Kehoe, M., Lleó, C., \& Rakow, M. (2004). Voice onset time in bilingual German-Spanish children. Bilingualism: Language and Cognition, 7(1), 71-88.

Kupisch, T. (2012). Generic subjects in the Italian of early German-Italian bilinguals and German learners of Italian as a second language. Bilingualism: Language and Cognition, 15(4), 736-756.

Kupisch, T. (2013). A new term for a better distinction? Theoretical Linguistics, 39(3-4), 203-214.

Kupisch, T. (2014). Adjective placement in simultaneous bilinguals (German-Italian) and the concept of cross-linguistic overcorrection. Bilingualism: Language and Cognition, 17(1), 222-233.

Kupisch, T., Akpinar, D., \& Stöhr, A. (2013). Gender assignment and gender agreement in adult bilingual and second language speakers of French. Linguistic Approaches to Bilingualism, 3(2), 150-179.

Kupisch, T., Lein, T., Barton, D., Schröder, D.J., Stangen, I., \& Stoehr, A. (2014). Acquisition outcomes across domains in adult simultaneous bilinguals with French as weaker and stronger language. Journal of French Language Studies, 24(3), 1-30.

Kupisch, T., \& Pierantozzi, C. (2010). Interpreting definite plural subjects: A comparison of German and Italian monolingual and bilingual children. In K. Franich, K. M. Iserman, \& L. L. Keil (Eds.), Proceedings of the 34th BUCLD (pp. 245-254). Boston, MA: Cascadilla Press.

Lein, T., Kupisch, T., \& van de Weijer, J. (2016). Voice onset time and global foreign accent in GermanFrench simultaneous bilinguals during adulthood. International Journal of Bilingualism, 20, 732-749. 
Lightfoot, D., \& Westergaard, M. (2007). Language acquisition and language change: Interrelationships. Language and Linguistics Compass, 1(5), 396-416.

Lleó, C., \& Cortés, S. (2013). Modelling the outcome of language contact in the speech of Spanish-German and Spanish-Catalan bilingual children. International Journal of the Sociology of Language, 221, 101125.

Luk, G., \& Bialystok, E. (2013). Bilingualism is not a categorical variable: Interaction between language proficiency and usage. Journal of Cognitive Psychology, 25, 605-621.

Meisel, J. M. (Ed.) (1990). Two first languages--early grammatical development in bilingual children. Dordrecht, The Netherlands: Foris.

Meisel, J. M. (Ed.) (1994a). Bilingual first language acquisition: French and German grammatical development. Amsterdam, Holland: John Benjamins.

Meisel, J. M. (Ed.) (1994b). La adquisición del vasco y del castellano en niños bilingües. Madrid/ Frankfurt: Vervuert Verlag.

Meisel, J. M. (2011). First and second language acquisition: Parallels and differences. Cambridge, UK: Cambridge University Press.

Meisel, J. M. (2013). Heritage language learners: Unprecedented opportunities for the study of grammars and their development? Theoretical Linguistics, 39(3-4), 225-236.

Montrul, S. (2008). Incomplete acquisition in bilingualism. Re-examining the age factor. Amsterdam, Holland: John Benjamins.

Montrul, S. (2016). The acquisition of heritage languages. Cambridge, UK: Cambridge University Press.

Montrul, S., \& Ionin, T. (2012). Dominant language transfer in Spanish heritage speakers and L2 learners in the interpretation of definite articles. The Modern Language Journal, 96(2), 70-94.

Montrul, S., \& Potowski, K. (2007). Command of gender agreement in school-age Spanish bilingual children. International Journal of Bilingualism, 11(3), 301-328.

Paradis, J., \& Genesee, F. (1996). Syntactic acquisition in bilingual children: Autonomous or interdependent? Studies in Second Language Acquisition, 18(1), 1-25.

Pascual y Cabo, D. (2013). Knowledge of gustar-like verbs in Spanish heritage speakers. In J. C. Amaro, T. Judy, \& D. Pascual y Cabo (Eds.), Proceedings of the 12th GASLA conference (pp. 162-169). Somerville, MA: Cascadilla Proceedings Project.

Pascual y Cabo, D., \& Rothman, J. (2012). The (il)logical problem of heritage speaker bilingualism and incomplete acquisition. Applied Linguistics, 33(4), 450-455.

Peal, E., \& Lambert, M. (1962). The relation of bilingualism to intelligence. Psychological Monographs, $76(546), 1-23$.

Pires, A., \& Rothman, J. (2009). Disentangling sources of incomplete acquisition: An explanation for competence divergence across heritage grammars. International Journal of Bilingualism, 13(2), 211-238.

Polinsky, M. (2011). Reanalysis in adult heritage language: A case for attrition. Studies in Second Language Acquisition, 33, 305-328

Polinsky, M. (2015) When L1 becomes an L3: Assessing grammatical knowledge in heritage speakers/learners. Bilingualism: Language and Cognition, 18, 163-378.

Polinsky, M., \& Kagan, O. (2007). Heritage languages: In the 'wild' and in the classroom. Language and Linguistics Compass, 1(5), 368-395.

Putnam, M., \& Sánchez, L. (2013). What's so incomplete about incomplete acquisition? A prolegomenon to modeling heritage language grammars. Linguistic Approaches to Bilingualism, 3(4), 476-506.

Rodina, Y., \& Westergaard, M. (2015). Grammatical gender in bilingual Norwegian-Russian acquisition: The role of input and transparency. Bilingualism: Language and Cognition. Advance Online Publication 18 September 2015. doi:10.1017/S1366728915000668.

Rothman, J. (2007). Heritage speaker competence differences, language change and input type: inflected infinitives in Heritage Brazilian Portuguese. International Journal of Bilingualism, 11(4), 359-389.

Rothman, J. (2009). Understanding the nature and outcomes of early bilingualism: Romance languages as heritage languages. International Journal of Bilingualism, 13(2), 155-163.

Rothman, J., \& Treffers-Daller, J. (2014). A prolegomenon to the construct of the native speaker: Heritage speaker bilinguals are natives too! Applied Linguistics, 35(1), 93-98. 
Saer, D. J. (1923). The effect of bilingualism on intelligence. British Journal of Psychology, 14, 28-38.

Schachter, J. (1990). On the issue of completeness in second language acquisition. Second Language Research, 6, 93-123.

Schlyter, S., \& Håkansson, G. (1994). Word order in Swedish as the first language, second language and weaker language in bilinguals. Scandinavian Working Papers on Bilingualism, 9, 49-66.

Schmidt, T., \& Wörner, K. (Eds) (2012). Multilingual corpora and multilingual corpus analysis. (pp. 107122). Amsterdam, Holland: John Benjamins.

Scontras, G., Fuchs, Z., \& Polinsky, M. (2015). Heritage language and linguistic theory. Frontiers in Psychology. Language Sciences [Internet]. Retrieved from http://dx.doi.org/10.3389/fpsyg.2015.01545

Serratrice, L., Sorace, A., Filiaci, F., \& Baldo, M. (2009). Bilingual children's sensitivity to specificity and genericity: evidence from metalinguistic awareness. Bilingualism: Language and Cognition, 12, 239267.

Sorace, A. (2004). Native language attrition and developmental instability at the syntax-discourse interface: Data, interpretations and methods. Bilingualism: Language and Cognition, 7, 143-145.

Tsimpli, I. M. (2014). Early, late or very late: Timing acquisition and bilingualism: A reply to peer commentaries. Linguistic Approaches to Bilingualism, 4(3), 393-402.

Valdés, G. (2000). Introduction. In Spanish for native speakers, Volume I. AATSP professional development series handbook for teachers K-16 (pp. 1-29). New York, NY: Harcourt College.

Valian, V. (2015). Bilingualism and cognition. A focus on mechanisms. Bilingualism: Language and Cognition, 18(1), 3-34.

Van Suchtelen, P. I. (2014). Maintained and acquired heritage Spanish in the Netherlands: The case of dative constructions. Applied Linguistics Review, 5(2), 375-400.

\section{Author biographies}

Tanja Kupisch is a Professor of Linguistics at the University of Konstanz as well as a Professor II of Linguistics at the UiT The Arctic University of Norway. She has conducted research on bilingual first language acquisition, first, second and third language acquisition, bilectal acquisition as well as language dominance. Her work has focussed on the syntax and semantics of Determiner Phrases and pronunciation.

Jason Rothman is a Professor of Multilingualism and Clinical Language Sciences at the University of Reading as well as a Professor II of Linguistics at UiT The Arctic University of Norway. He has conducted research on first, second and third language acquisition as well as heritage language bilingualism, with a particular focus on the acquisition of morphosyntax. His research makes use of a diverse range of behavioral, psychoand neurolinguistic methodologies to investigate quantitative and qualitative aspects of linguistic competence in different groups of learners. 